This item was submitted to Loughborough's Research Repository by the author.

Items in Figshare are protected by copyright, with all rights reserved, unless otherwise indicated.

\title{
Laser sintered body armour - establishing single layer stab protection
}

PLEASE CITE THE PUBLISHED VERSION

http://dx.doi.org/10.1108/RPJ-11-2015-0173

PUBLISHER

(c) Emerald

VERSION

AM (Accepted Manuscript)

PUBLISHER STATEMENT

This work is made available according to the conditions of the Creative Commons Attribution-NonCommercialNoDerivatives 4.0 International (CC BY-NC-ND 4.0) licence. Full details of this licence are available at: https://creativecommons.org/licenses/by-nc-nd/4.0/

\section{LICENCE}

CC BY-NC-ND 4.0

\section{REPOSITORY RECORD}

Johnson, Andrew, Guy Bingham, and Candice E. Majewski. 2018. "Laser Sintered Body Armour - Establishing Single Layer Stab Protection”. Loughborough University. https://hdl.handle.net/2134/24653. 


\section{Emerald Rapid Prototyping Journal}

\section{Laser sintered body armour - establishing single layer stab protection}

\begin{tabular}{|r|l|}
\hline Journal: & Rapid Prototyping Journal \\
\hline Manuscript ID & RPJ-11-2015-0173.R1 \\
\hline Manuscript Type: & Original Article \\
\hline Keywords: & Selective laser sintering, Body armour, Stab protection, Protective clothing \\
\hline \multicolumn{2}{|c}{} \\
\hline
\end{tabular}

\section{SCHOLARONE \\ Manuscripts}




\section{Laser sintered body armour - establishing single layer stab protection}

\section{Purpose:}

The purpose of this research was to establish the minimum thickness required to provide stab protection in accordance with the United Kingdom Home Office Scientific Development Branch (HOSDB) standards while testing a series of Laser Sintered planar specimens using instrumented test apparatus.

\section{Design/methodology/approach:}

Planar test specimens were Laser Sintered in single layer thicknesses ranging from 1.00 to $15.00 \mathrm{~mm}$ in four material powder categories - Duraform ${ }^{\circledR}$ virgin; Duraform ${ }^{\circledR} 50 / 50$ mix, Duraform EX ${ }^{\circledR}$ virgin; and Duraform $E X{ }^{\circledR}$ 50/50 mix. All specimens were tested using instrumented drop test apparatus and were impacted with established Stanley Tools 1992 trimming blades to the UK HOSDB KR1-E1 stab impact energy.

\section{Findings:}

The research demonstrated that a minimum single planar specimen thickness of $11.00 \mathrm{~mm}$, manufactured from Duraform $\mathrm{EX}{ }^{\circledR} 50 / 50$ mix powder, was required to provide protection against the HOSDB KR1-E1 level of stab impact energy. The alternative powder mixes tested within this experiment demonstrated poor levels of stab protection - with virgin powder specimens demonstrating no protection up to $15.00 \mathrm{~mm}$, while Duraform ${ }^{\circledR} 50 / 50 \mathrm{mix}$ specimens demonstrating inconsistent performances.

Originality/Value:

This paper enhances on existing literature surrounding the manufacturing and testing of Additive Manufactured stab resistant armour by adding further rigor to the testing of such specimens. In addition this research establishes key foundation characteristics which could be utilised for the future development of bespoke next-generation body armour garments realised via Laser Sintering.

Keywords:

Laser Sintering; body armour; stab protection; 3D printed textiles; protective clothing 


\section{Introduction}

The primary aim of any body armour garment is to minimise the likelihood of its wearer sustaining life threatening injuries (Ashdown 1909). Throughout history this aim has been achieved using a range of techniques including the use of animal hide, highly decorated cuirass assemblies, or more recently through the use of aramid fibre panels and Polycarbonate plates (Scott 2005; Ffoulkes 1909). Despite modern armour providing protection to stringent protective standards established by the United Kingdom Home Office Scientific Development Branch (HOSDB) (Croft \& Longhurst 2007a; Croft \& Longhurst 2007c), their fundamental design have been shown to hinder the operational manoeuvrability and thermal regulation of its wearer (Dempsey et al. 2013).

Additive manufacturing (AM) technologies are being utilised in an increasing number of novel applications - from customised wrist splints and industrial grade gripping solutions, to high performance stab resistant textiles manufactured via Laser Sintering (LS) (Paterson et al. 2015; SCHUNK GmbH \& Co. 2015; Johnson et al. 2013). By utilising the inherent design freedom provided by such technologies, there is a growing opportunity to manufacture highly protective body armour that also begins to address historical concerns relating to wearer manoeuvrability and thermal comfort (Dempsey et al. 2013).

Previously published research has investigated the use of AM technologies for the manufacture of body armour, including the development of monolithic solutions via Laminated Object Manufacturing (LOM), bio-inspired and multi-layered AM armour, and the analysis of material extruded modelled stab resistant links (Klosterman et al. 1999; Rudykh et al. 2015; Johnson et al. 2015; Maidin \& Seeying 2016). In addition, previous research has established that a minimum Laser Sintered single planar thickness of $8.00 \mathrm{~mm}$ was required to successfully provide stab protection within HOSDB guidelines - with specimens manufactured from Polyamide (PA) 2200 using a 50:50 mix of virgin and recycled powder. However, it should be noted that all experimental tests performed within this original proof-of-concept body of work used an in-house manufactured drop test impact rig and in-house manufactured HOSDB P1/B specification blades (Johnson et al. 2013).

More recently the stab performance of the HOSDB P1/B blade was assessed against the Stanley 1992 trimming blade - arguably a more credible real-world and readily available threat (Johnson 2014). Results from this recent investigation determined that when stab tested against HOSDB KR1 certified body armour specimens, the Stanley 1992 trimming 
blades demonstrated greater levels of blade penetration than the P1/B blades at the same impact energy of 24 Joules (Johnson 2014).

Whilst recognising the limitations experienced within the original outlined proof-ofconcept research, this body of work advances knowledge relating to the stab resistant performance of single thickness planar specimens through the utilisation of established instrumented test apparatus. The primary objective of this experiment was therefore to assess the stab resistant performance of single thickness LS test specimens manufactured from two common polymer materials using both virgin and a commonly refreshed powder mixture, against the Stanley 1992 trimming blade.

\section{Experimental methodology}

\subsection{Specimen materials}

Two common PA based materials purchased from 3D Systems ${ }^{\mathrm{TM}}$ were used for the manufacture of test specimens:

- $\quad$ Duraform ${ }^{\circledR}(3 \mathrm{D}$ Systems 2013)

- Duraform EX® (3D Systems Corporation 2008)

Test specimens were manufactured from both 100\% virgin, and a 50/50 mix of virgin and recycled powder using both Duraform ${ }^{\circledR}$ and Duraform $\mathrm{EX}^{\circledR}$ materials. In total four builds were performed using an EOS P100 Formiga LS machine:

- Group one: Virgin Duraform ${ }^{\circledR}$ powder

- Group two: 50/50 Duraform ${ }^{\circledR}$ powder

- Group three: Virgin Duraform EX® powder

- Group four: 50/50 Duraform EX® powder

The recycled constituents of the Duraform ${ }^{\circledR}$ and Duraform EX ${ }^{\circledR}$ powders were generated from any non-sintered powder from the build volume along with any pre-warmed powder within the build chamber and hopper system. Previous research has established that powder that has been used for less than 20 hours build time or $200 \mathrm{~mm}$ build height, is of good quality to be used in a refresh/recycled format (Dotchev \& Yusoff 2009). 


\subsection{Test specimen geometry}

The main body of each specimen measured $60 \times 60 \mathrm{~mm}$ in length and width, and ranged in thickness from 1.00 to $15.00 \mathrm{~mm}$ in $1 \mathrm{~mm}$ increments. Three specimens were manufactured per thickness, with each featuring an identification tab. In total 45 test specimens were manufactured per material group, with 180 tested across this experiment overall.

\subsection{Test specimen manufacture}

All test specimens were manufactured by the Additive Manufacturing Research Group (AMRG) at Loughborough University using an EOS P100 Formiga LS machine, as shown within Figure 1.

Figure 1. EOS P100 Formiga Laser Sintering machine (A), Empty build chamber (B), LS build bed applied (C) \& Powder tumbler (D)

\subsection{Build parameters}

Previously established processing parameters for each of the four material groups were used - these parameters have been optimised to ensure the successful manufacture of specimens for testing, and are outlined within Table 1 (Johnson 2014).

Table 1. Laser sintering process parameters

Table 1 highlights that a number of parameters, most notably part bed temperature and warm-up time were greater when using Duraform EX ${ }^{\circledR}$ powder. This was due to the material processing window for the Duraform EX ${ }^{\circledR}$ powder (Polyamide 11 based) being much smaller than that of the Duraform ${ }^{\circledR}$ powder (Polyamide 12 based), and was consequently more susceptible to changes in temperature (Goodridge et al. 2012). Therefore by increasing the temperature and pre-heating the machine and powder for a longer period, previous literature demonstrated that Polyamide 11 based sintered parts were less prone to failure during the build process (Goodridge et al. 2012). 


\subsection{Build location and orientation}

To minimise the likelihood of any potential performance effects as a result of part positioning within the build volume, the placement of each specimen was randomised across six positions on eight different layers - this is shown within Figure 2. In addition, the numbering scheme shown within Figure 2 designates the thickness of each specimen along with its sample number. For example, a designation on layer one of ' $6 / 1$ ' indicates a specimen of 6 mm thick of which it is the first of three related to that particular thickness.

Figure 2. Experimental build layout

In line with established literature, test specimens were orientated to ensure the dimension for specimen thickness was perpendicular to the build platform, thus ensuring densities and fracture strengths were maximised (Caulfield et al. 2007; Gibson \& Shi 2007). In addition, specimens were centered on the $200 \times 250 \mathrm{~mm}$ build platform of the EOS P100 Formiga LS machine. A powder base layer of $3.00 \mathrm{~mm}$ was applied to the build platform during preparation, with an additional $2.00 \mathrm{~mm}$ of powder was applied during the warm up phase. A $5.00 \mathrm{~mm}$ spacing between each sample in $\mathrm{X}$ and $\mathrm{Y}$-directions was maintained, while a $3.00 \mathrm{~mm}$ spacing between specimens in the Z-direction was established. To complete the build and to assist with controlled cooling, a $5.00 \mathrm{~mm}$ thick layer of powder was applied on top of the completed sintered parts - establishing a total build height of $99 \mathrm{~mm}$.

\subsection{Build procedure}

A detailed operational procedure for preparing the CAD build files, the steps taken to initiate each LS build, and for the post-process of specimens to remove any residual powder were established (Johnson 2014).

\subsection{Stab testing experimental design}

Each stab tests used a virgin Stanley 1992 trimming blade. In total 180 specimens were tested across four material groups - with 45 tests per group. The order in which samples were tested was randomised to minimise the effects of any uncontrollable variables. Backing material trays were used for one test before being rotated - with the backing material being 
reformed between each test to ensure trays maintained thermal conditioning.

\subsection{Stab test methodology}

\subsubsection{Drop tower apparatus}

All stab tests were performed using an 'Instron $9250 \mathrm{HV}$ ' instrumented drop tower, as shown within Figure 3.

Figure 3. Instron 9250HV drop tower

The total mass of the drop weight assembly, including blade chuck was calibrated at $6.50 \mathrm{~kg}$. Velocity detecting apparatus was also used to validate the performance of each drop test and ensure the desired impact energy was reached.

\subsubsection{Backing material}

Roma Plastilina ${ }^{\circledR}$ No. 1 clay was used as the backing material for all tests, and was housed within a set of three steel fabricated trays - as shown within Figure 4.

Figure 4. Roma Plastilina ${ }^{\circledR}$ No. 1 clay backing tray

Prior to experimentation, each backing tray was thermally conditioned at $30^{\circ} \mathrm{C}$ for a period of three hours using an Alpha $190 \mathrm{H}$ temperature chamber - in line with UK HOSDB body armour standards (Croft \& Longhurst 2007b; Green 1978). During testing the backing trays were temporarily secured to the bed of the drop tower.

\subsubsection{Test and environmental requirements}

All drop tests were performed to the UK HOSDB KR1-E1 impact energy of $24 \mathrm{~J}$, were performed in an ambient environment within a temperature range of $21^{\circ} \mathrm{C}+/-6$, and a relative humidity range of $30-70 \%$ as defined by the HOSDB (Croft \& Longhurst 2007c). The 
experimental test requirements used on the Instron 9250HV drop tower are outlined within Table 2.

Table 2. Stab test experimental requirements

Test specimens demonstrating no blade penetration through their underside, or a level of blade penetration at or below $7.00 \mathrm{~mm}$ is identified as providing a successful level of stab protection within the UK HOSDB standards.

\subsubsection{Test blades}

All tests performed within this body of work featured use of the Stanley Tools 1992 trimming blade - one of the most common utility blades currently available. A summary of the specification of the Stanley blade and view of the blade assembly is shown within Figure 5 and Figure 6 respectively.

Figure 5. Stanley Tools 1992 Trimming Blade Specification

Figure 6. Stanley 1992 Trimming Blade Assembly

Within Figure 6, the jig component was used to orientate the blade to ensure the double sided cutting edges of the blade contacted the strike surface of the test specimen.

\subsubsection{Recording blade penetration}

Blade penetration through the underside of test specimens were directly measured using digital callipers (Johnson 2014) - as demonstrated within Figure 7.

Figure 7. Measuring blade penetration 


\subsubsection{Detailed manufacturing and test procedures}

Detailed procedures relating to the manufacture of all test specimens and operation of test apparatus were established. Further information relating to these can be found within $\mathrm{PhD}$ thesis - "Establishing design characteristics for the development of stab resistant Laser Sintered body armour" (Johnson 2014).

\section{Experimental results}

Results from this experiment are presented in the following sub-sections by material category.

\subsection{Duraform ${ }^{\circledR}$ - Virgin}

Specimens manufactured using virgin Duraform ${ }^{\circledR}$ powder in thicknesses ranging from 1.00 to $15.00 \mathrm{~mm}$ proved ineffective at providing stab protection against the Stanley 1992 trimming blade threat to the UK HOSDB KR1-E1 impact energy of 24 Joules. An overview of the measured blade penetration depths are presented within Table 3.

Table 3. Blade penetration depth of each material test group

As documented, 37 of the 45 samples manufactured across all thicknesses within the virgin Duraform ${ }^{\circledR}$ material group demonstrated the maximum $30 \mathrm{~mm}$ of blade penetration through the underside of the specimens. In $92 \%$ of these cases the test samples fractured or shattered, as shown within Figure 8.

Figure 8. Virgin Duraform ${ }^{\circledR} 2.00 / 3$ test specimen

The eight positive results were found in specimens ranging in thickness from 8.00 to $15.00 \mathrm{~mm}$, with no single thickness group demonstrating a consistent level of blade penetration resistance across all three test specimens. Of the positive results, only four 
demonstrated stab penetration resistance where the test sample did not fracture or shatter, while the remaining four specimens shattered - as demonstrated in Figure 9.

Figure 9. Virgin Duraform ${ }^{\circledR} 8.00 / 3$ specimen (left) and 10.00/1 test specimen (right)

When stab testing the $8.00 / 3$ test specimen, the blade shattered before penetrating the underside of the test sample. However, the result from testing the 10.00/1 specimen showed that the test blade caused a significant level of damage to the sample - enough to cause it to fracture before the blade failed. Such blade failure occurred in all eight of the positive results documented. This failure was a likely result of the need to transfer kinetic energy away from the drop vehicle once impacted with the test sample - therefore shattering the test blade offered the path of least resistance.

In summary, the stab resistive performance of test specimens manufactured from the virgin Duraform ${ }^{\circledR}$ material group was poor and offered no consistent stab resistant thickness.

\subsection{Duraform ${ }^{\circledR}-50 / 50$}

The results from the stab testing of specimens manufactured from a 50/50 mix of virgin and recycled Duraform ${ }^{\circledR}$ are also presented within Table 3.

Test specimens ranging in thickness from 1-10 mm demonstrated inadequate stab resistance - with all specimens shattering or fracturing, to allow full blade penetration. The $11.00 \mathrm{~mm}$ thick test specimen group was the first to demonstrate a consistent level of stab protection, with no blade penetration registered across all three samples - as shown in Figure 10 .

Figure 10. $11.00 \mathrm{~mm}$ thick test specimens manufactured from 50/50 mix Duraform ${ }^{\circledR}$

Two of the three positive results within this thickness group not only demonstrated test blade failure, but also featured the shattering of the test specimen. The first thickness group to demonstrate a consistent and positive level of blade penetration resistance without specimen failure was that of the $15.00 \mathrm{~mm}$ group, as shown in Figure 11. 
Figure 11. $15.00 \mathrm{~mm}$ thick test specimens manufactured from 50/50 mix Duraform ${ }^{\circledR}$

All three $15.00 \mathrm{~mm}$ thick specimens shown within Figure 11 registered zero blade penetration - successfully demonstrating stab resistance. Instead, the Stanley 1992 trimming blades shattered.

\subsection{Duraform $E X^{\circledR}-$ Virgin}

When manufactured from virgin Duraform $\mathrm{EX}^{\circledR}$ powder all specimens in thicknesses below $11.00 \mathrm{~mm}$ failed to demonstrate penetration resistance within the $7.0 \mathrm{~mm}$ HOSDB limit. Six of the 15 specimens between 11-15 mm thick provided appropriate levels of penetration resistance, however, no single thickness group demonstrated a consistent level of stab protection across all three test specimens. A summary of results from this material group are documented within Table 3.

When compared against the results previously obtained from testing Duraform ${ }^{\circledR}$ samples, the results document that specimens ranging in thickness from 1-3 mm prevented full penetration of the blade to be reached - suggesting they demonstrate some resistance. This is illustrated within Figure 12.

Figure 12. Failure mode comparison between $3.00 \mathrm{~mm}$ thick virgin Duraform $\mathrm{EX} \AA(\mathrm{left})$ and virgin Duraform ${ }^{\circledR}$ (Right) specimens

Instead of shattering like the previously tested virgin Duraform ${ }^{\circledR}$ samples, the 3.00 mm thick virgin Duraform EX ${ }^{\circledR}$ test specimen appeared to have absorbed a degree of the stab impact energy - causing the specimen to deform on its underside and begin to fracture. This resistive behaviour however did not extend beyond the $3.00 \mathrm{~mm}$ thick specimens - with those above failing via a shattering mode.

\subsection{Duraform $E X^{\circledR}-50 / 50$}

The final material group to be tested was that of specimens manufactured from a 50/50 consistency virgin and recycled Duraform $\mathrm{EX}^{\circledR}$. The results from the stab testing of these 
specimens are outlined within Table 3.

Positive results were demonstrated with a number of the samples in the 9.00 and $10.00 \mathrm{~mm}$ thickness groups. These results were however not consistent until the specimen thickness increased to $11.00 \mathrm{~mm}$ - with all succeeding samples within the test group also showing positive results. Stab protection achieved with $11.00 \mathrm{~mm}$ thick 50/50 Duraform EX® specimens is shown within Figure 13.

Figure 13. 11.00/1 test specimen manufactured from 50/50 mix Duraform EX®

Within these positive results, the Stanley test blade shattered, resulting in the tip of the blade left residing within the strike surface of the test specimens. All of the specimens which demonstrated a positive result showed no signs of fracturing on either their strike or underside surfaces.

It should also be noted that when testing 50/50 mix Duraform EX ${ }^{\circledR}$ specimens, the mode of failure for those up to and including $6.00 \mathrm{~mm}$ thick was a puncturing mode, while test specimens beyond this thickness demonstrated fracturing and shattering failure modes. When compared to the results from stab testing virgin and recycled Duraform ${ }^{\circledR}$, and virgin Duraform EX ${ }^{\circledR}$, this mode of failure occurred up to a greater thickness than in previous experiments - suggesting the material is more suitable at absorbing stab impact energy.

\section{Conclusions}

All tests were performed to the UK HOSDB KR1-E1 stab impact energy of 24 Joules using Stanley Tools 1992 trimming blades. A summary of test results, highlighting minimum single thickness requirements are outlined within Table 4.

Table 4. Summary of single thickness stab resistant minimum requirements

The results from this investigation demonstrate an increase in the minimum thickness is required to provide stab protection to the UK HOSDB KR1-E1 impact energy of 24 Joules - in comparison to previously published proof-of-concept research (Johnson et al. 2013). Although such is the case this research has demonstrated a significant step towards the 
development of stab resistant AM body armour through the utilisation of established instrumented test apparatus, rather than in-house manufactured apparatus as used in previous proof-of-concept research.

No virgin powder test specimens were successful with single thicknesses up to 15.00

$\mathrm{mm}$. However, the test results do suggest that stab resistance is achieved when using 50/50 mix powder across both Duraform ${ }^{\circledR}$ and Duraform EX ${ }^{\circledR}$ material groups - albeit inconsistent performance when using Duraform ${ }^{\circledR}$. The only material group to demonstrate a consistent level of stab protection at and above $11.00 \mathrm{~mm}$ thick was that of the Duraform EX ${ }^{\circledR} 50 / 50$ mix group. This enhanced mechanical performance may be attributed to the increased molecular weight as a result of prior thermal loading of the recycled powder within the Duraform EX® 50/50 mix (Zarringhalam et al. 2006; Gibson et al. 2010).

It should be recognised that a number of limitations are apparent with this research. For example, the experimental test procedure utilised within this body of work is based on world leading and established HOSDB stab test procedures relating to the testing of traditional aramid-fibre and polycarbonate armour systems. Modifications were required to ensure the instrumented drop test apparatus was suitable for testing additive manufactured specimens. In addition, as previously stated stab testing was performed using the more potent Stanley 1992 trimming blade rather than the identified HOSDB P1/B blade. By successfully demonstrating stab protection against the more severe blade, there are high levels of confidence that successful stab protection would also be achieved using the less severe HOSDB P1/B blade within any body armour certification testing.

By successfully establishing a LS single layer thickness that provides stab protection, there is the potential to the drive the development of the next-generation of protective body armour via the utilisation of LS technologies. The results of which may influence the development of protective solutions that provide high levels of protection without restricting the operational manoeuvrability of its wearer.

\section{Further work}

Based on the results obtained from this experiment, further research investigating the development of stab resistant AM body armour should be focused on the use of 50/50 mix Duraform $\mathrm{EX}^{\circledR}$ powder over the alternatives used within this experiment. 
In addition, the results obtained from this experiment have highlighted a number of areas which if investigated could further advance the development of stab resistant AM body armour. Such areas include:

(1) The potential development of thinner layers arranged to create multi-layered specimens. Initial results in the outlined experiments suggested that thinner specimens offered some degree of resistance; therefore multiple thin layers may demonstrate a reduced total thickness required to achieve stab protection.

(2) A detailed investigation between the ratio of virgin and recycled powder to determine whether a greater level of recycled powder enhances stab protective performance.

(3) The potential to explore further LS materials such as metal-filled and ceramic-filled polymers.

(4) An opportunity to explore the protective performance of AM armour featuring composite and/or cellular based internal structures.

(5) Using all established design characteristics for the design, manufacture, and testing of articulated textiles.

(6) Assessment of established AM/LS armour against blunt force and ballistic threats. 


\section{References}

3D Systems, 2013. DuraForm ${ }^{\circledR}$ Laser Sintering (SLS) Materials. Available at: http://production3dprinters.com/materials/sls [Accessed March 5, 2013].

3D Systems Corporation, 2008. DuraForm EX® Plastic. Available at: http://www.3dsystems.com/sites/www.3dsystems.com/files/DS_DuraForm_EX_US.pdf [Accessed April 10, 2011].

Ashdown, C., 1909. British and foreign arms \& armour, London: TC \& EC Jack.

Caulfield, B., Mchugh, P. \& Lohfeld, S., 2007. Dependence of mechanical properties of polyamide components on build parameters in the SLS process. Journal of Materials Processing Technology, 182, pp.477-488.

Croft, J. \& Longhurst, D., 2007a. HOSDB Body Armour Standards for UK Police (2007) Part 1: General Requirements - 39/07/A, United Kingdom: Crown.

Croft, J. \& Longhurst, D., 2007b. HOSDB Body Armour Standards for UK Police (2007) Part 2: Ballistic Resistance, United Kingdom: Crown.

Croft, J. \& Longhurst, D., 2007c. HOSDB Body Armour Standards for UK Police (2007) Part 3: Knife and Spike Resistance - 39/07/C, United Kingdom: Crown.

Dempsey, P., Handcock, P. \& Rehrer, N., 2013. Impact of police body armour and equipment on mobility. Applied ergonomics, pp.1-5. Available at: http://www.ncbi.nlm.nih.gov/pubmed/23668780 [Accessed June 26, 2013].

Dotchev, K. \& Yusoff, W., 2009. Recycling of polyamide 12 based powders in the laser sintering process. Rapid Prototyping Journal, 15(3), pp.192-203. Available at: http://www.emeraldinsight.com/10.1108/13552540910960299 [Accessed August 13, 2011].

Ffoulkes, C., 1909. Armour \& weapons, Oxford: Clarendon Press. Available at: http://scholar.google.com/scholar?hl=en\&btnG=Search\&q=intitle:Armour+and+Weapo ns\#4 [Accessed August 1, 2011].

Gibson, I., Rosen, D. \& Stucker, B., 2010. Additive Manufacturing Technologies, New York: Springer. Available at: http://www.springerlink.com/index/10.1007/978-1-4419-1120-9 [Accessed August 23, 2011].

Gibson, I. \& Shi, D., 2007. Material properties and fabrication parameters in selective laser sintering process. Rapid Prototyping Journal, 3(4), pp.129-136.

Goodridge, R., Tuck, C. \& Hague, R., 2012. Laser sintering of polyamides and other polymers. Progress in Materials Science, 57(2), pp.229-267. Available at: http://linkinghub.elsevier.com/retrieve/pii/S0079642511000648 [Accessed July 20, 2011].

Green, M., 1978. Stab Wound Dynamics - A Recording Technique for Use in Medico-Legal 
Investigations. Journal of Forensic Science Society, 18, pp.161-163.

Johnson, A., 2014. Establishing design characteristics for the development of stab resistant Laser Sintered body armour. PhD Thesis. Loughborough Design School. Loughborough University. Available at: https://dspace.lboro.ac.uk/dspace-jspui/handle/2134/16743.

Johnson, A., Bingham, G. \& Wimpenny, D., 2013. Additive manufactured textiles for highperformance stab resistant applications. Rapid Prototyping Journal, 19(3), pp.199-207. Available at: http://www.emeraldinsight.com/10.1108/13552541311312193 [Accessed May 8, 2014].

Johnson, A.A., Bingham, G.A. \& Majewski, C.E., 2015. Laser sintered body armour: establishing guidelines for dual-layered stab protection. International Journal of Rapid Manufacturing, 5(1), p.3. Available at: http://www.inderscience.com/link.php?id=73545.

Klosterman, D. et al., 1999. Development of a curved layer LOM process for monolithic ceramics and ceramic matrix composites. Rapid Prototyping Journal, 5(2), pp.61-71.

Maidin, S. \& Seeying, C., 2016. Finite element analysis of Additive Manufactured textiles for stab resistant applications. ARPN Journal of Engineering and Applied Sciences, 11(3), pp.1529-1535.

Paterson, A. et al., 2015. Comparing additive manufacturing technologies for customised wrist splints. Rapid Prototyping Journal, 21(3), pp.230-243.

Rudykh, S., Ortiz, C. \& Boyce, M., 2015. Flexibility and protection by design: Imbricated hybrid microstructures of bio-inspired armor. Soft Matter, 11(13), pp.2547-2554. Available at: http://dx.doi.org/10.1039/C4SM02907K.

SCHUNK GmbH \& Co., 2015. eGRIP. Online. Available at: http://www.schunkprodukte.com/en/tools/3d-designtool-egrip.html [Accessed May 19, 2015].

Scott, R., 2005. Textiles for protection, Cambridge: Woodhead Publishing Limited.

Zarringhalam, H. et al., 2006. Effects of processing on microstructure and properties of SLS Nylon 12. Materials Science and Engineering A, 435-436, pp.172-180. 

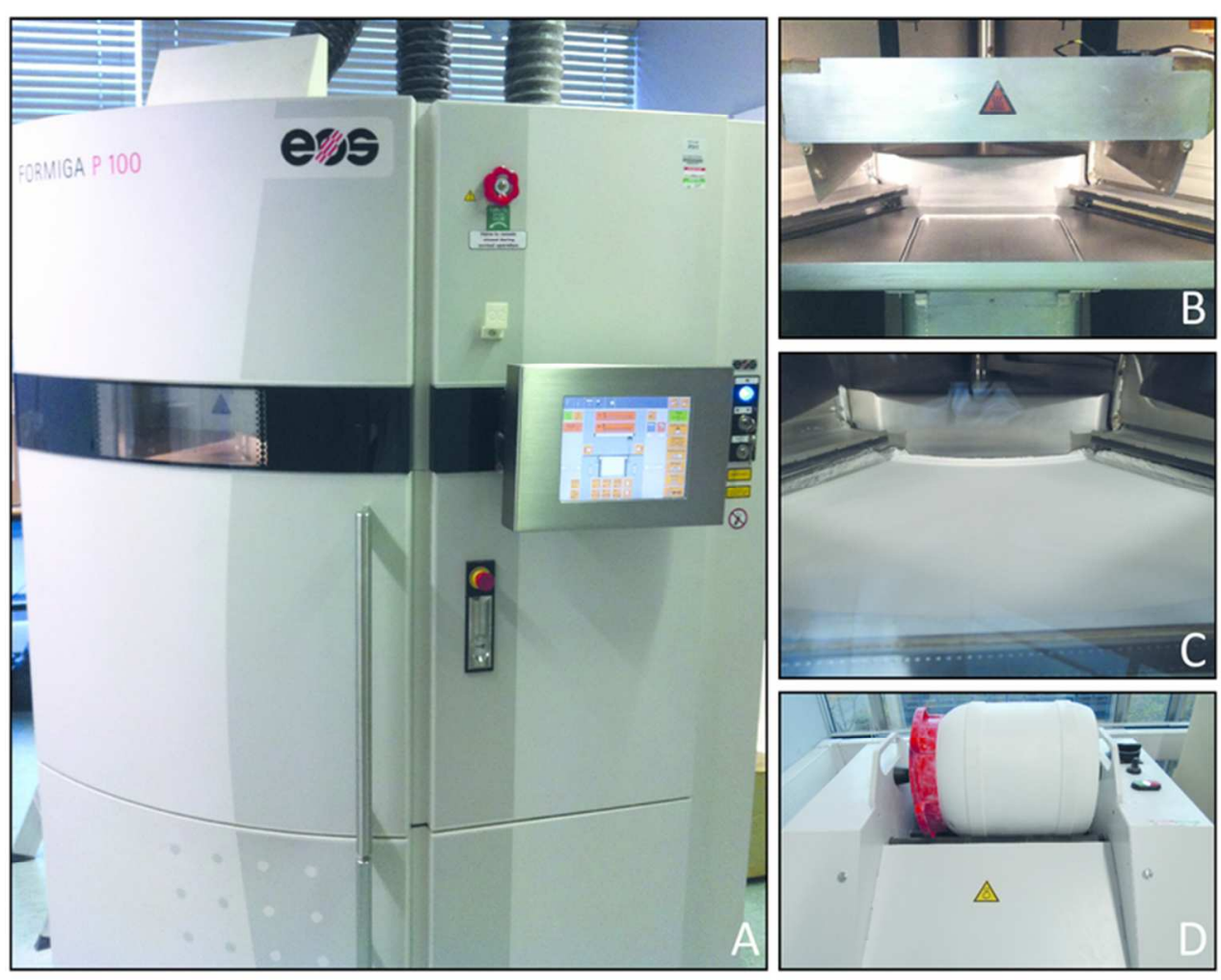

Figure 1. EOS P100 Formiga Laser Sintering machine (A), Empty build chamber (B), LS build bed applied (C) \& Powder tumbler (D)
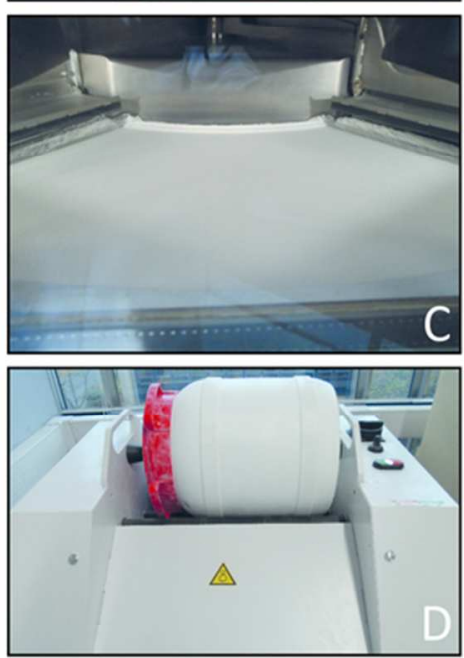
Figure 1 $135 \times 107 \mathrm{~mm}(150 \times 150 \mathrm{DPI})$ 
1

2

3

4

5

6

7

8

9

10

11

12

13

14

15

16

17

18

19

20

21

22

23

24

25

26

27

28

29

30

31

32

33

34

35

36

37

38

39

40

41

42

43

44

45

46

47

48

49

50

51

52

53

54

55

56

57

58

59

60

Table 1. Laser sintering process parameters

\begin{tabular}{lcc}
\hline Parameter & Duraform ${ }^{\circledR}$ & Duraform EX® \\
\hline Layer thickness & $0.1 \mathrm{~mm}$ & $0.1 \mathrm{~mm}$ \\
Part bed temperature & $172.5^{\circ} \mathrm{C}$ & $178.5^{\circ} \mathrm{C}$ \\
Laser Power & $18 \mathrm{~W}$ & $22 \mathrm{~W}$ \\
Scan Speed & $1,500 \mathrm{~mm} / \mathrm{s}$ & $3,000 \mathrm{~mm} / \mathrm{s}(3.0 \mathrm{~m} / \mathrm{s})$ \\
Warm-up time & 150 minutes & 300 minutes \\
\hline
\end{tabular}



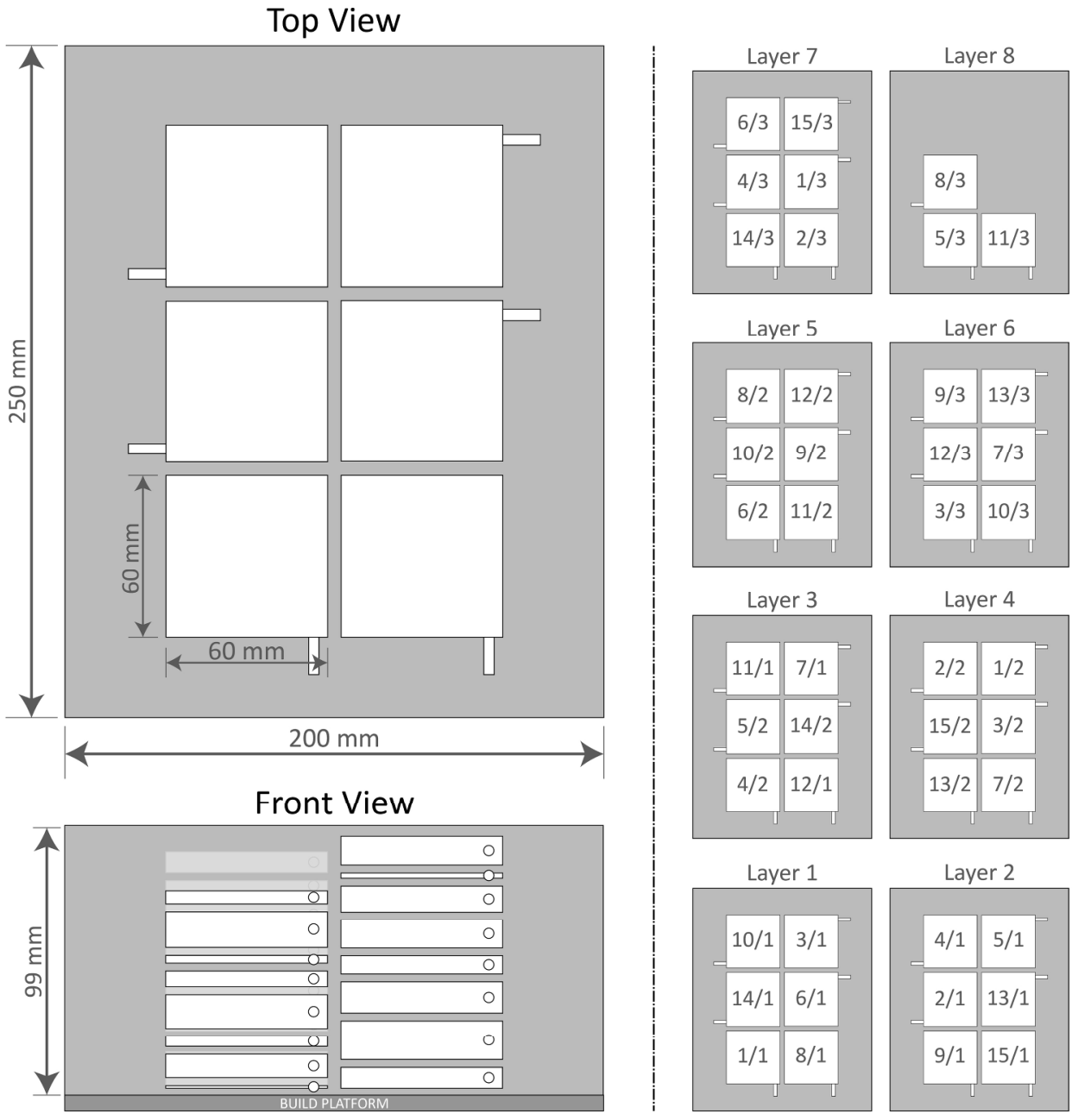

Figure 2. Experimental build layout Figure 2 $451 \times 469 \mathrm{~mm}(150 \times 150 \mathrm{DPI})$ 


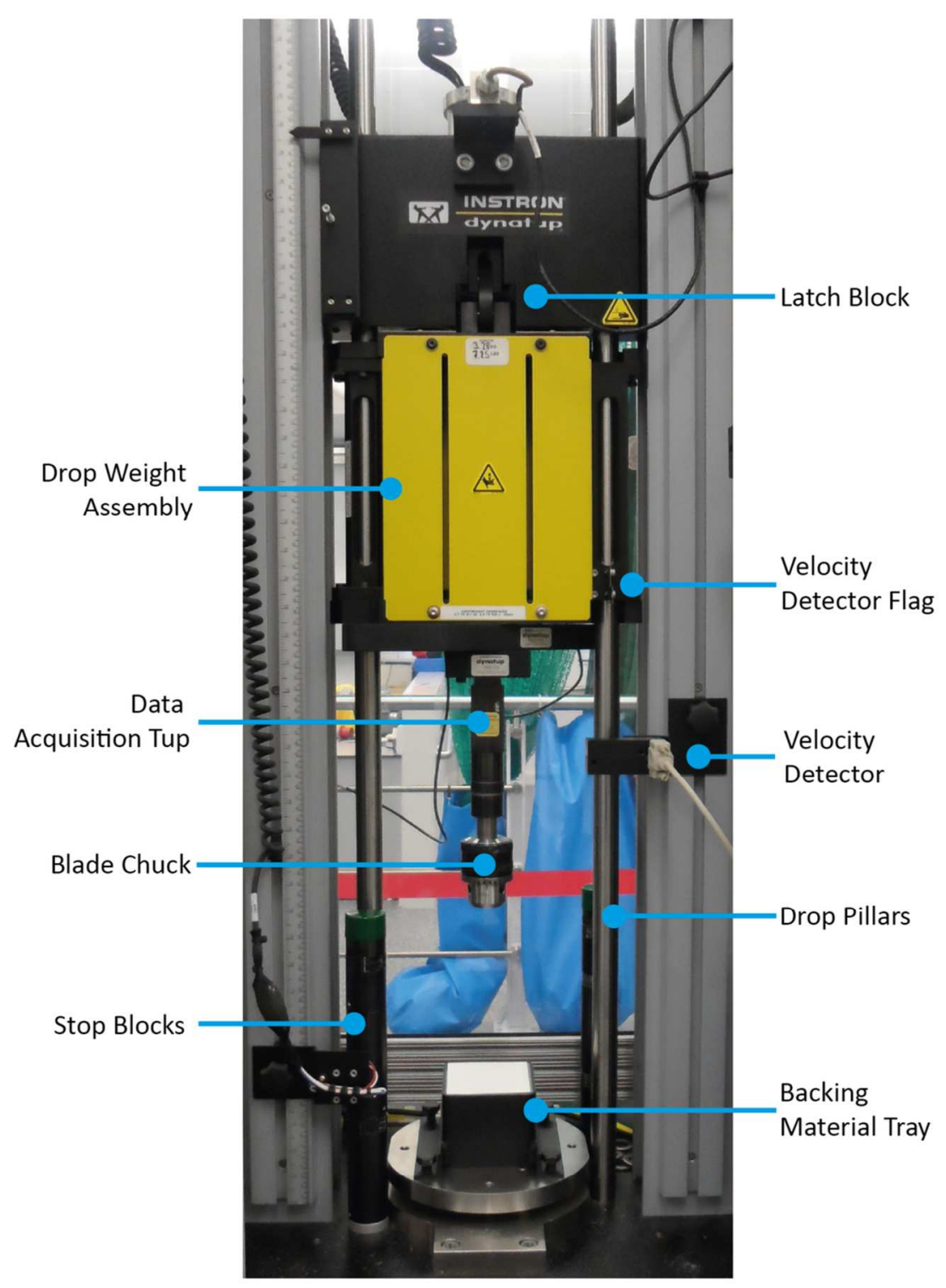

Figure 3. Instron 9250HV drop tower

Figure 3 $187 \times 255 \mathrm{~mm}(150 \times 150 \mathrm{DPI})$ 


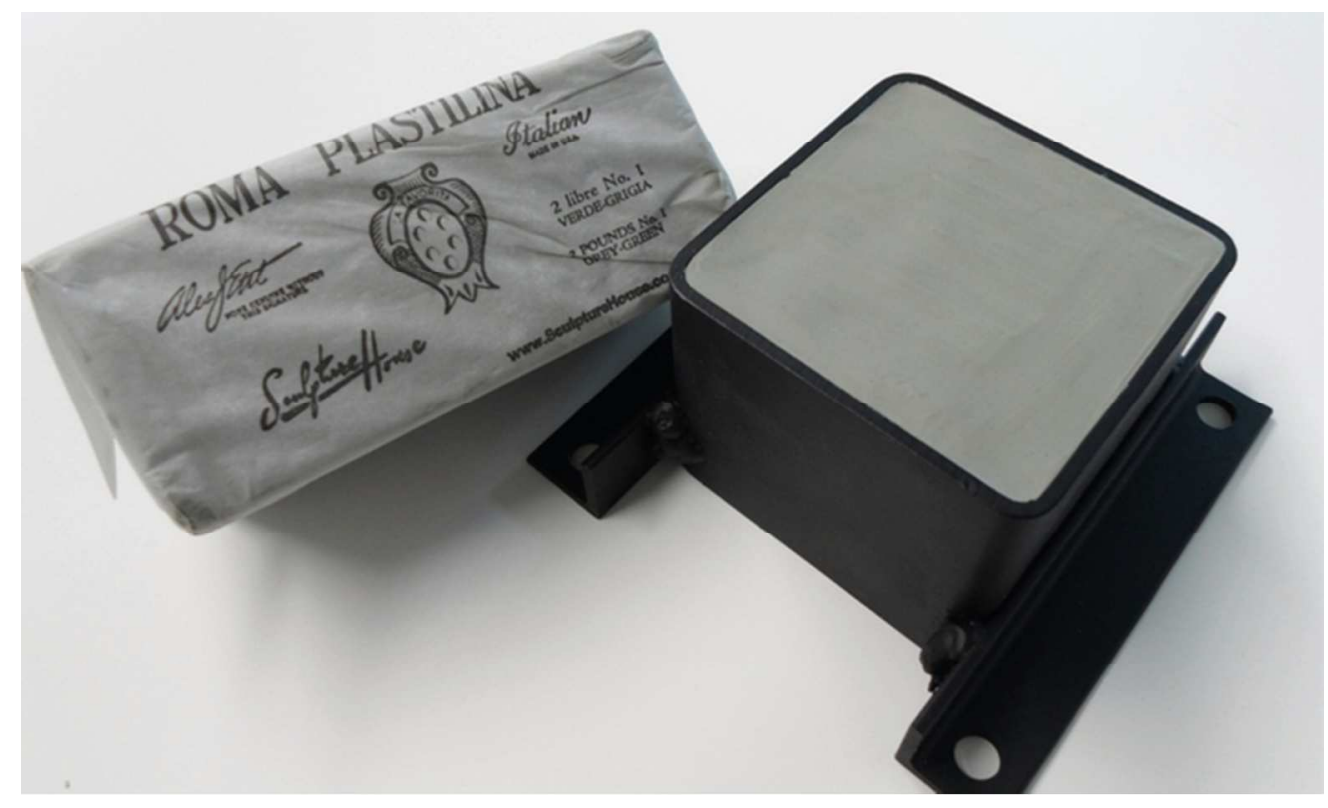

Figure 4. Roma Plastilina ${ }^{\circledR}$ No. 1 clay backing tray Figure 4 $118 \times 71 \mathrm{~mm}(150 \times 150$ DPI $)$ 
1

2

3

4

5

6

7

8

9

10

11

12

13

14

15

16

17

18

19

20

21

22

23

24

25

26

27

28

29

30

31

32

33

34

35

36

37

38

39

40

41

42

43

44

45

46

47

48

49

50

51

52

53

54

55

56

57

58

59

60

Table 2. Stab test experimental requirements

\begin{tabular}{cccccc}
\hline $\begin{array}{c}\text { Energy } \\
\text { Level }\end{array}$ & $\begin{array}{c}\text { Stab Energy } \\
\text { (Joule) }\end{array}$ & $\begin{array}{c}\text { Drop } \\
\text { Mass }(\mathrm{kg})\end{array}$ & $\begin{array}{c}\text { Drop } \\
\text { Height }(\mathrm{m})\end{array}$ & $\begin{array}{c}\text { Drop Velocity } \\
(\mathrm{m} / \mathrm{s})\end{array}$ & $\begin{array}{c}\text { Maximum Blade } \\
\text { Penetration (mm) }\end{array}$ \\
\hline KR1-E1 & $24+/-0.5$ & 6.50 & 0.376 & 2.716 & 7.00 \\
\hline
\end{tabular}


Figure 5. Stanley Tools 1992 Trimming Blade Specification Figure 5

\section{Trimming Blade}

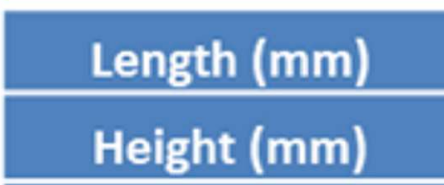

Thickness (mm) Mass $(\mathrm{g})$

\section{Angle between}

cutting edges $\left({ }^{\circ}\right)$

\section{Material}

\section{Manufacturer}

62.00

19.00

0.65

3.80

\section{5}

\section{Stanley Black \& Decker UK Ltd \\ Polished steel (grade unknown)}




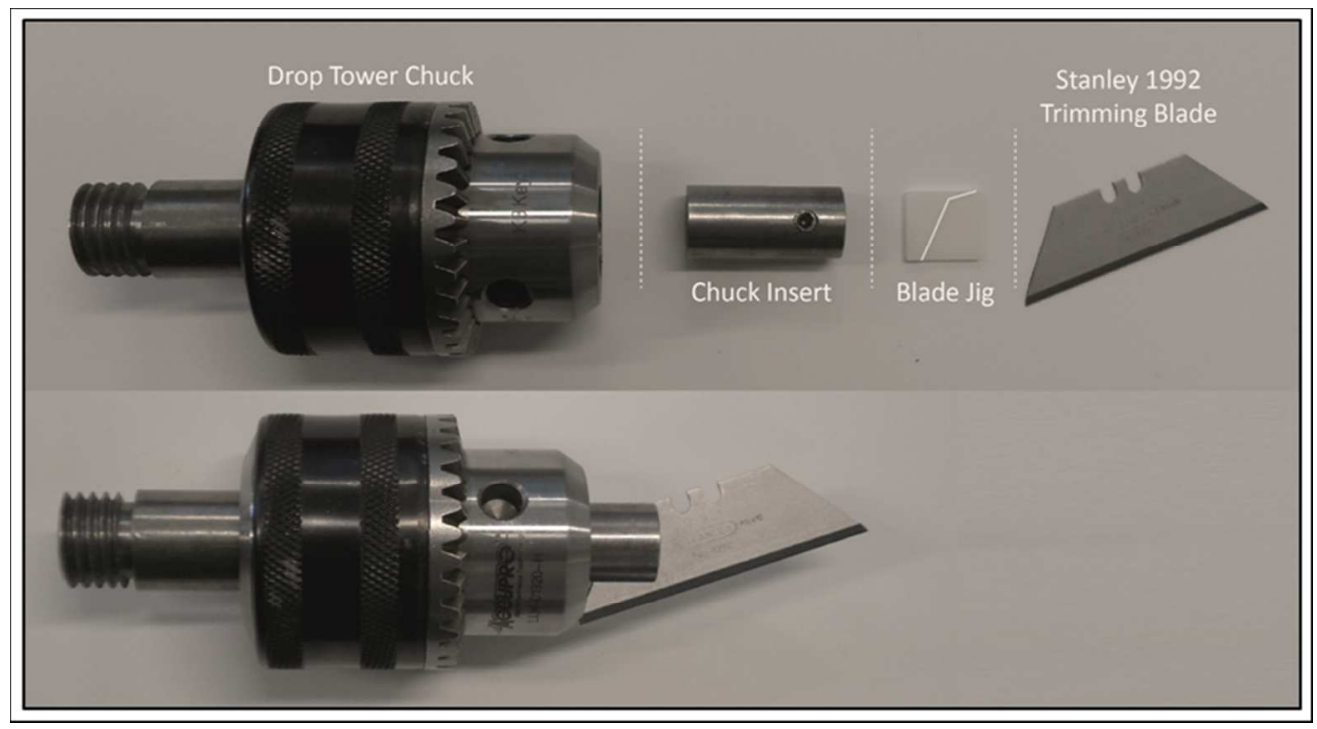

Figure 6. Stanley 1992 Trimming Blade Assembly Figure 6 $169 \times 93 \mathrm{~mm}(150 \times 150 \mathrm{DPI})$ 


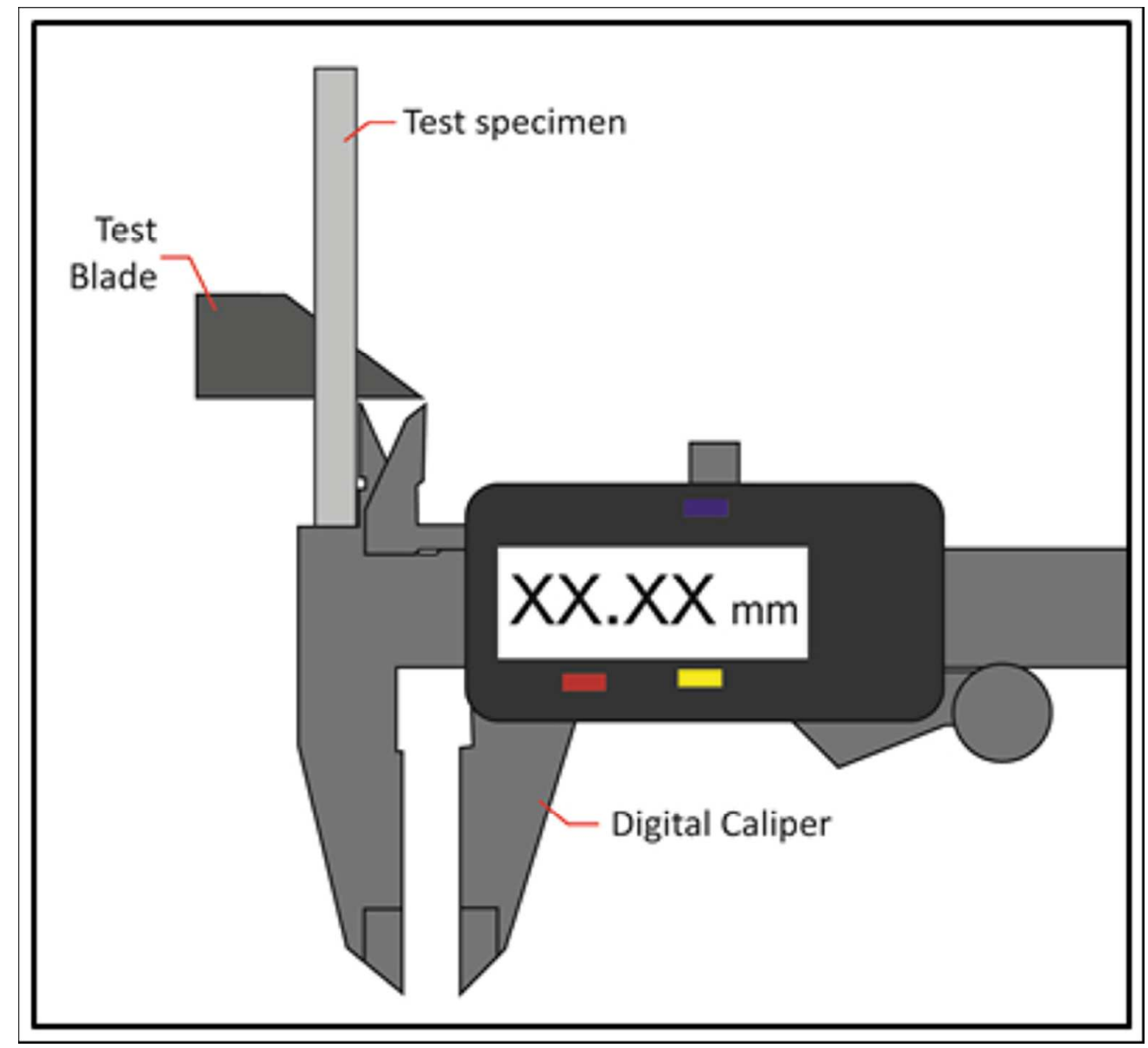

Figure 7. Measuring blade penetration Figure 7 $124 \times 114 \mathrm{~mm}(150 \times 150 \mathrm{DPI})$ 
Table 3. Blade penetration depth of each material test group

\begin{tabular}{|c|c|c|c|c|c|}
\hline & & & & & \\
\hline \multirow[b]{2}{*}{ No. } & \multirow[b]{2}{*}{ Specimen ID } & \multicolumn{4}{|c|}{ Blade Penetration Depth (mm) } \\
\hline & & $\begin{array}{l}\text { Duraform }{ }^{\circledR} \\
\text { Virgin }\end{array}$ & $\begin{array}{l}\text { Duraform }{ }^{\circledR} \\
50 / 50 \mathrm{mix}\end{array}$ & $\begin{array}{c}\text { Duraform } \\
\text { EX® Virgin }\end{array}$ & $\begin{array}{c}\text { Duraform EX® } \\
50 / 50 \mathrm{mix}\end{array}$ \\
\hline 1 & $01.00 / 1$ & 30.00 & 30.00 & 30.00 & 30.00 \\
\hline 2 & $01.00 / 2$ & 30.00 & 30.00 & 27.84 & 30.00 \\
\hline 3 & $01.00 / 3$ & 30.00 & 30.00 & 29.82 & 30.00 \\
\hline 4 & $02.00 / 1$ & 30.00 & 30.00 & 29.91 & 28.67 \\
\hline 5 & $02.00 / 2$ & 30.00 & 30.00 & 28.93 & 29.74 \\
\hline 6 & $02.00 / 3$ & 30.00 & 30.00 & 28.04 & 30.00 \\
\hline 7 & $03.00 / 1$ & 30.00 & 30.00 & 30.00 & 29.54 \\
\hline 8 & $03.00 / 2$ & 30.00 & 30.00 & 28.21 & 30.00 \\
\hline 9 & $03.00 / 3$ & 30.00 & 29.97 & 30.00 & 30.00 \\
\hline 10 & $04.00 / 1$ & 30.00 & 30.00 & 30.00 & 30.00 \\
\hline 11 & $04.00 / 2$ & 30.00 & 30.00 & 30.00 & 30.00 \\
\hline 12 & $04.00 / 3$ & 30.00 & 30.00 & 30.00 & 30.00 \\
\hline 13 & $05.00 / 1$ & 30.00 & 30.00 & 30.00 & 30.00 \\
\hline 14 & $05.00 / 2$ & 30.00 & 30.00 & 30.00 & 30.00 \\
\hline 15 & $05.00 / 3$ & 30.00 & 30.00 & 30.00 & 28.08 \\
\hline 16 & $06.00 / 1$ & 30.00 & 30.00 & 30.00 & 30.00 \\
\hline 17 & $06.00 / 2$ & 30.00 & 30.00 & 30.00 & 30.00 \\
\hline 18 & $06.00 / 3$ & 30.00 & 30.00 & 30.00 & 30.00 \\
\hline 19 & $07.00 / 1$ & 30.00 & 30.00 & 30.00 & 30.00 \\
\hline 20 & $07.00 / 2$ & 30.00 & 30.00 & 30.00 & 30.00 \\
\hline 21 & $07.00 / 3$ & 30.00 & 30.00 & 30.00 & 30.00 \\
\hline 22 & $08.00 / 1$ & 30.00 & 29.55 & 30.00 & 29.00 \\
\hline 23 & $08.00 / 2$ & 30.00 & 30.00 & 30.00 & 30.00 \\
\hline 24 & $08.00 / 3$ & 0.00 & 30.00 & 30.00 & 30.00 \\
\hline 25 & $09.00 / 1$ & 30.00 & 30.00 & 30.00 & 28.65 \\
\hline 26 & $09.00 / 2$ & 30.00 & 30.00 & 30.00 & 0.00 \\
\hline 27 & $09.00 / 3$ & 30.00 & 30.00 & 30.00 & 30.00 \\
\hline 28 & $10.00 / 1$ & 2.36 & 30.00 & 30.00 & 0.00 \\
\hline 29 & $10.00 / 2$ & 30.00 & 30.00 & 30.00 & 24.38 \\
\hline 30 & $10.00 / 3$ & 30.00 & 30.00 & 30.00 & 0.00 \\
\hline 31 & $11.00 / 1$ & 0.00 & 0.00 & 30.00 & 0.00 \\
\hline 32 & $11.00 / 2$ & 30.00 & 0.00 & 0.00 & 0.00 \\
\hline 33 & $11.00 / 3$ & 5.53 & 0.00 & 30.00 & 0.00 \\
\hline 34 & $12.00 / 1$ & 30.00 & 5.98 & 30.00 & 0.00 \\
\hline 35 & $12.00 / 2$ & 30.00 & 30.00 & 30.00 & 0.00 \\
\hline 36 & $12.00 / 3$ & 0.00 & 2.20 & 5.83 & 0.00 \\
\hline 37 & $13.00 / 1$ & 1.89 & 0.00 & 30.00 & 0.00 \\
\hline 38 & $13.00 / 2$ & 30.00 & 14.16 & 0.00 & 0.00 \\
\hline 39 & $13.00 / 3$ & 30.00 & 0.00 & 0.00 & 0.00 \\
\hline 40 & $14.00 / 1$ & 0.00 & 0.00 & 30.00 & 0.00 \\
\hline 41 & $14.00 / 2$ & 30.00 & 0.00 & 14.30 & 0.00 \\
\hline 42 & $14.00 / 3$ & 30.00 & 11.71 & 30.00 & 0.00 \\
\hline 43 & $15.00 / 1$ & 0.00 & 0.00 & 30.00 & 0.00 \\
\hline 44 & $15.00 / 2$ & 30.00 & 0.00 & 3.55 & 0.00 \\
\hline 45 & $15.00 / 3$ & 30.00 & 0.00 & 0.00 & 1.56 \\
\hline \multicolumn{2}{|c|}{ Mean Impact Energy (J) } & 23.70 & 23.66 & 23.65 & 23.66 \\
\hline \multicolumn{2}{|c|}{ Mean Impact Velocity $(\mathrm{m} / \mathrm{s})$} & 2.70 & 2.70 & 2.70 & 2.70 \\
\hline
\end{tabular}




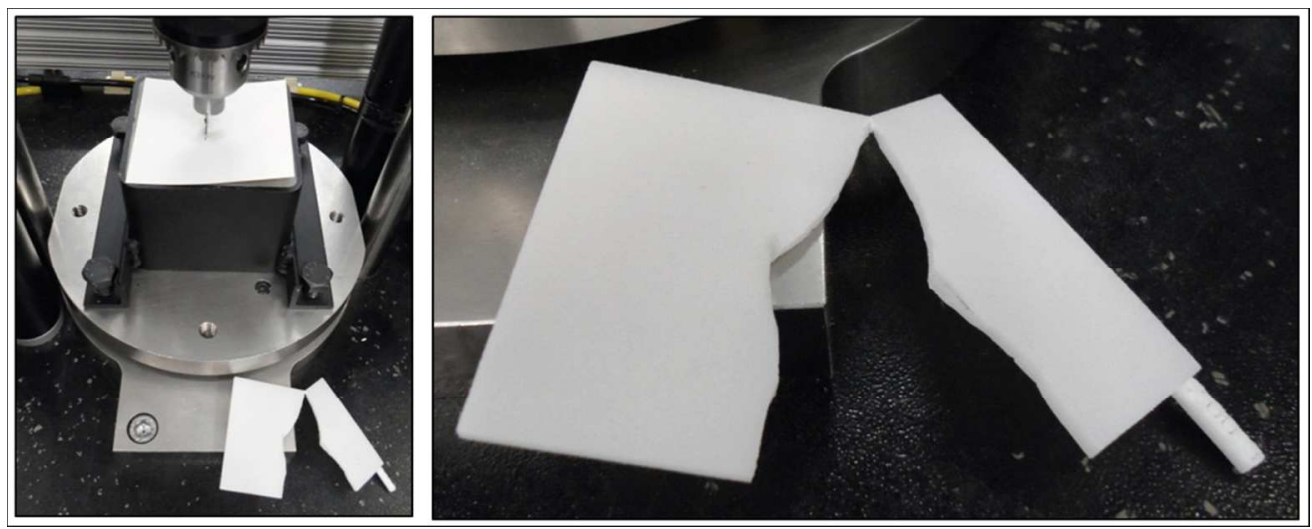

Figure 8. Virgin Duraform $® 2.00 / 3$ test specimen Figure 8

$234 \times 93 \mathrm{~mm}(150 \times 150 \mathrm{DPI})$ 


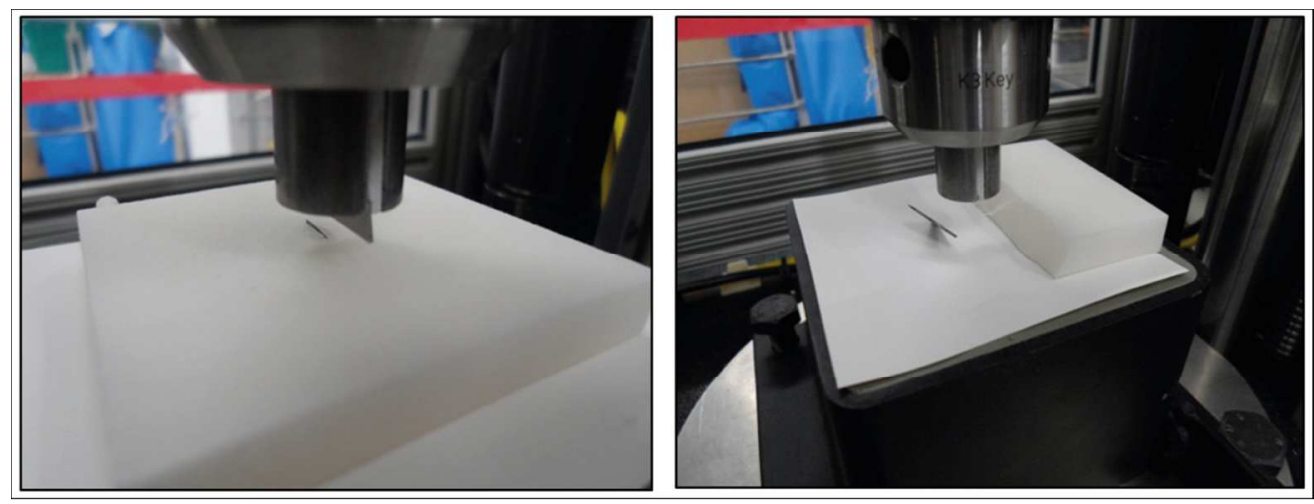

Figure 9. Virgin Duraform ${ }^{\circledR} 8.00 / 3$ specimen (left) and 10.00/1 test specimen (right) Figure 9 $237 \times 89 \mathrm{~mm}(150 \times 150 \mathrm{DPI})$ 


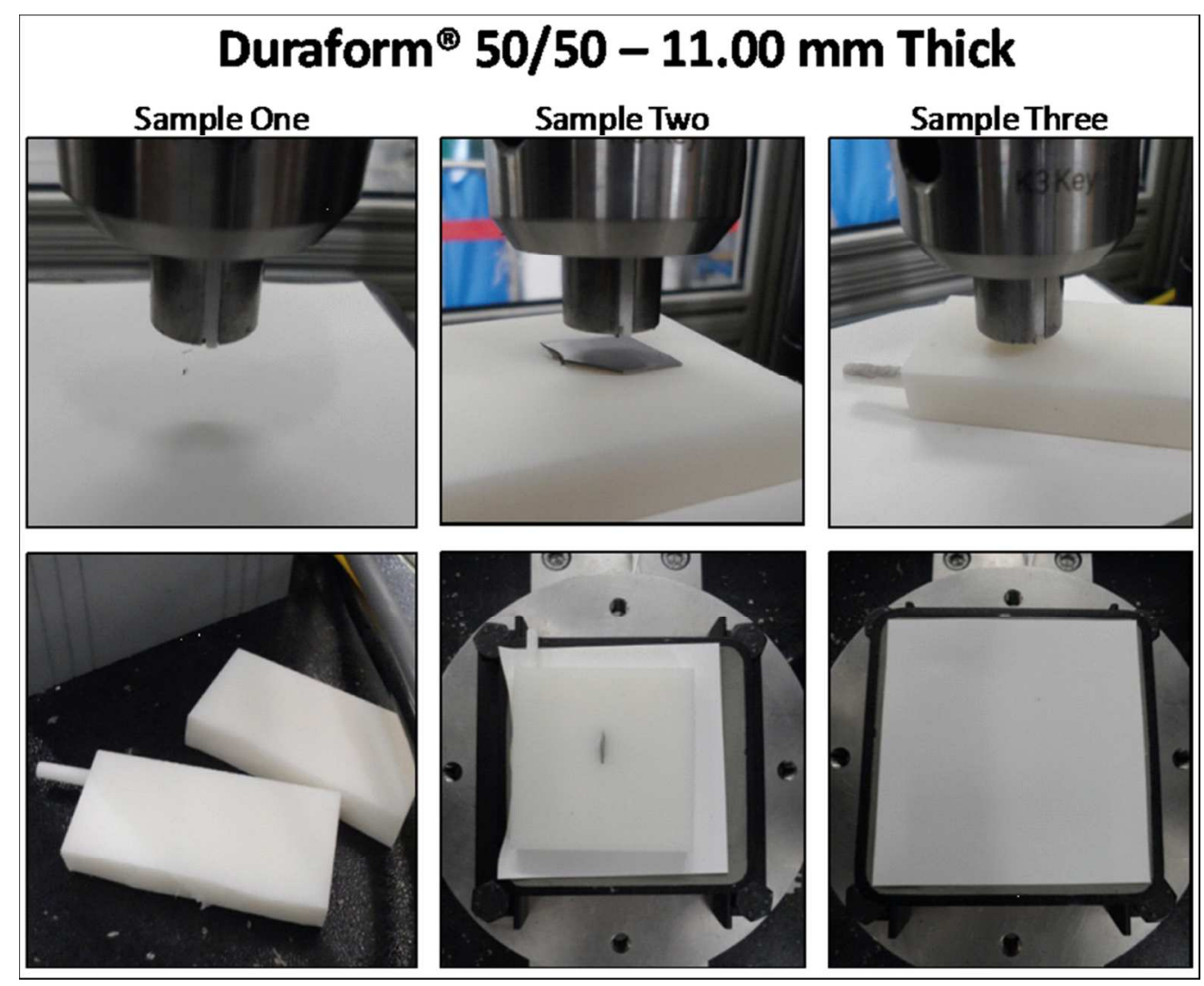

Figure 10. $11.00 \mathrm{~mm}$ thick test specimens manufactured from 50/50 mix Duraform $\AA$ Figure 10 


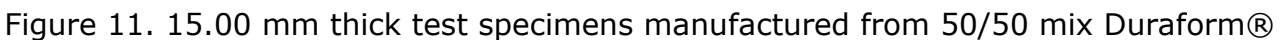
Figure 11 


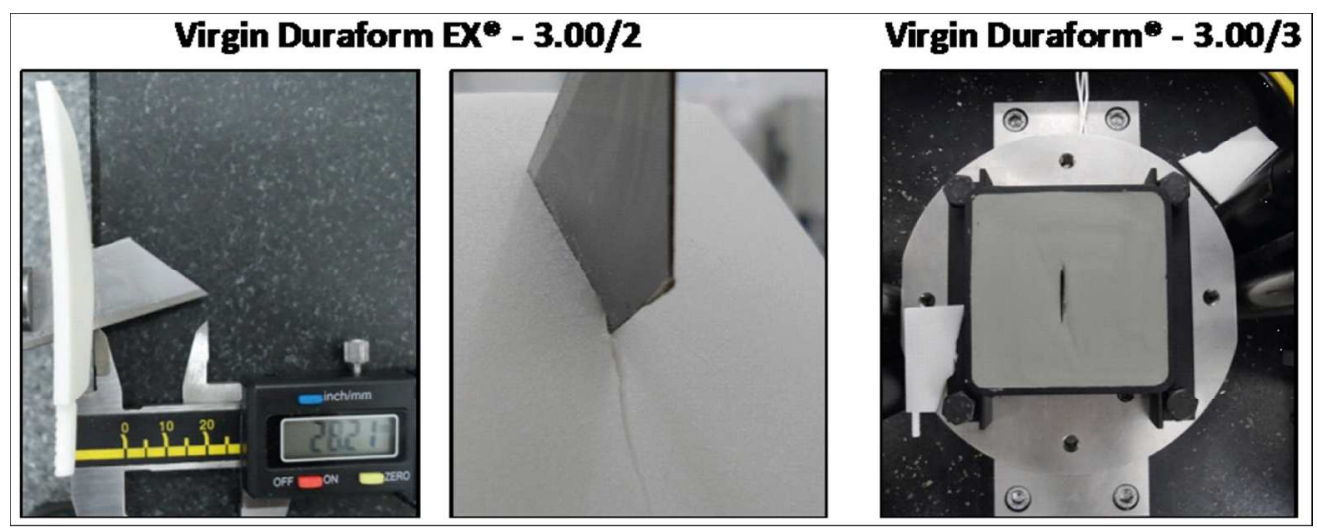

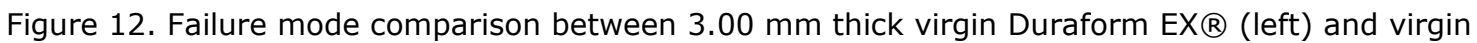
Duraform $®$ (Right) specimens Figure 12 $238 \times 94 \mathrm{~mm}(150 \times 150 \mathrm{DPI})$ 


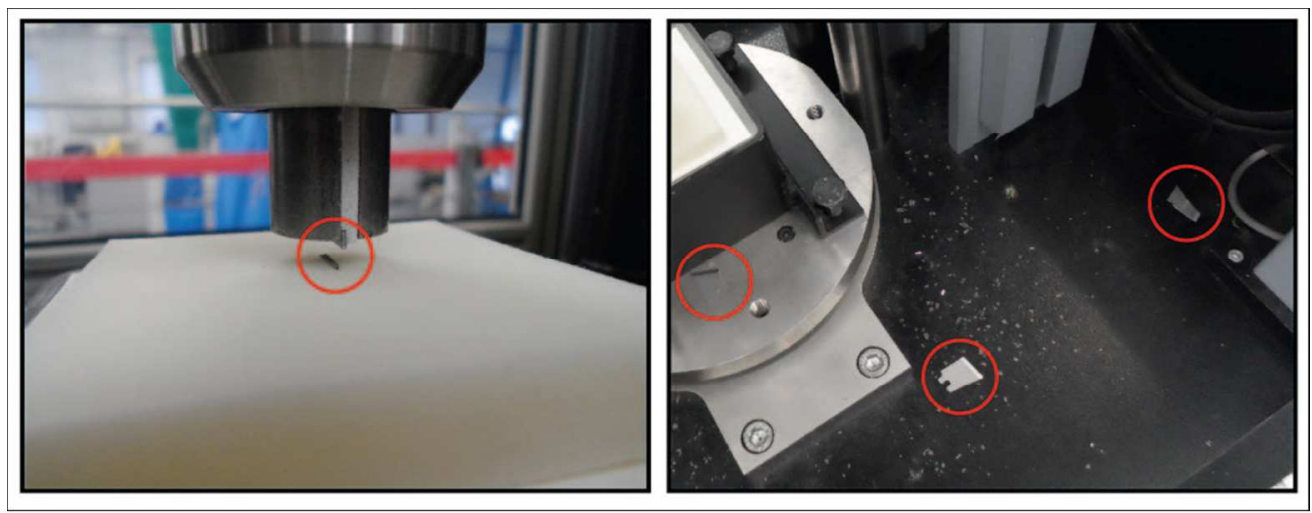

Figure 13. 11.00/1 test specimen manufactured from 50/50 mix Duraform EX® Figure 13 $224 \times 86 \mathrm{~mm}(150 \times 150$ DPI $)$ 
Table 4. Summary of single thickness stab resistant minimum requirements

\begin{tabular}{cc}
\hline Material & Minimum thickness \\
\hline Duraform ${ }^{\circledR}$ Virgin & No minimum achieved \\
Duraform ${ }^{\circledR} \mathbf{5 0 / 5 0 ~} \mathbf{~ m i x}$ & Initial $11.00 \mathrm{~mm}$ \\
Duraform EX ${ }^{\circledR}$ Virgin & (Inconsistent at greater thicknesses) \\
Duraform EX ${ }^{\circledR 0 / 50 ~} \mathbf{~ m i x}$ & No minimum achieved \\
\hline
\end{tabular}

